\title{
ENTRE COMEMORAÇÕES, TENSÕES E CONSTRANGIMENTOS: INGRESSO NA UNIVERSIDADE PELO SISTEMA DE COTAS
}

\author{
Andrea Bayerl Mongim ${ }^{(*)}$ \\ Osvaldo Martins de Oliveira ${ }^{(* *)}$
}

O acesso ao ensino superior, no Brasil, vem se configurando por um quadro de desigualdades significativas, estando ainda bem distante do ideal de universalidade, uma vez que, conforme destacam Carvalho e Waltenberg (2015), menos de 20\% da população adulta do país consegue ingressar em uma Instituição de Ensino Superior.

Diante de tal conjuntura, instauraram-se na agenda política brasileira, sobretudo a partir dos anos 1990, diferentes iniciativas voltadas para ampliar o acesso a esse nível de ensino. Merecem destaque a implementação de ações afirmativas na modalidade de reserva de vagas para ingresso em instituições de ensino superior públicas e de bolsas para ingresso em instituições privadas.

Embora pesquisadores de diferentes áreas acadêmicas já tenham se dedicado à análise da mencionada problemática, produções relativas a esse contexto têm sido constituídas, em boa parte dos casos, por pesquisas de caráter quantitativo, documental e bibliográfico. Situando-nos em perspectiva antropológica, no presente estudo, buscamos nos aproximar das experiências cotidianas de estudantes que ingressaram em uma instituição de ensino superior, mediante sistema de reserva de vagas. Definimos como objetivo central proceder à análise do processo de ingresso e permanência desses discentes em um espaço onde, historicamente, foram excluídos e, ainda hoje, em muitos casos, constituem minoria. Analisamos as relações que estabelecem com agentes sociais posicionados nesse espaço de alteridade, destacando desafios, tensões e constrangimentos.

Assumindo uma proposta de pesquisa etnográfica, privilegiamos como lócus de referência, para o trabalho de campo, o universo institucional onde, cotidianamente, compartilham experiências estudantes inscritos nos cursos de Arquitetura e Urbanismo, Ciências Sociais, Direito e Medicina, da Universidade Federal do Espírito Santo. O trabalho de observação teve início durante o segundo semestre de 2011, estendendo-se até o ano de 2015. Foram realizadas observações em diferentes situações da vida acadêmica, desde o momento de efetivação da matrícula de calouros à

\footnotetext{
${ }^{(*)}$ Universidade Federal do Espírito Santo.

${ }^{(* *)}$ Universidade Federal do Espírito Santo.
} 
participação em aulas, seminários, movimentos reivindicatórios, encontros na cantina e nos corredores. Fizemos opção pela realização de entrevistas do tipo "narrativas de vida”, conforme perspectiva proposta pelo sociólogo Bertaux (1997). Considerando que o termo "história de vida" apresenta-se de forma pouco conveniente, uma vez que não distingue a história vivida por uma pessoa e o relato feito por ela, Bertaux (1997) elege por opção epistemológicas “narrativas de vida” como unidade de análise. O autor assim o faz compreendendo que o termo se apresenta de forma epistemologicamente mais adequada, uma vez que um relato pessoal somente corresponde a uma aproximação da história objetivamente ou subjetivamente vivida por alguém. Portanto, ao optar pela reconstituição da história de vida de alguém, exclusivamente através do seu próprio relato, o pesquisador somente tem a ilusão de tê-lo feito.

De acordo com Bertaux (1997, p. 6), “o relato de vida resulta de uma forma particular de entrevista, uma entrevista narrativa, ao curso da qual um pesquisador solicita a uma pessoa, denominada sujeito, a contar toda ou parte de sua experiência vivida”. O sociólogo diferencia “mundo social” de “categorias de situação”, demonstrando que estas não necessariamente são partes constituintes do primeiro. Citando como exemplos de categorias de situação mães que criam seus filhos sozinhas, pais divorciados, toxicômanos e estrangeiros em situação irregular, Bertaux enfatiza a diversidade de contextos. Tais situações, em sua perspectiva, só configuram "situações sociais em comum” na medida em que engendram "regras e lógicas de ação que apresentam pontos em comum: é percebida através de esquemas coletivos e, eventualmente, tratada por uma mesma instituição” (BERTAUX, 1997, p. 15).

No caso desta pesquisa, definimos como “categoria de situação” estudantes universitários, oriundos de famílias de baixa renda que, entre o semestre do ano de 2008 e o segundo do ano de 2015, ingressaram nos cursos de Arquitetura e Urbanismo, Ciências Sociais, Direito e Medicina, da Universidade Federal do Espírito Santo, mediante programa de reserva de cotas. Com o objetivo de analisar comparativamente o perfil de estudantes que ingressaram na UFES em período anterior e posterior à implantação do primeiro e do segundo sistema de cotas adotado pela Instituição, também fizemos uso de métodos e técnicas de coleta de dados quantitativos. Organizamos uma série histórica com base em dados coletados e previamente organizados pela Comissão Coordenadora do Vestibular (CCV-UFES) a partir de questionário respondido pelos estudantes no momento que se inscreveram para o processo seletivo. 


\section{AÇÕES AFIRMATIVAS E POLÍTICA DE COTAS PARA INGRESSO NA UNIVERSIDADE}

Conforme explica Munanga (2003. p. 80) “as ações afirmativas visam oferecer aos grupos discriminados e excluídos um tratamento diferenciado para compensar as desvantagens devidas à sua situação de vítimas do racismo e de outras formas de discriminação”.

Por essa via e, reconhecendo a situação de extrema desvantagem a que foi submetida à população negra no Brasil, agentes sociais afiliados ao Movimento Negro têm atuado como protagonistas de amplo movimento em torno da implantação de programas de reserva de cotas raciais para ingresso no ensino superior. Afinal, conforme dados apresentados por Henriques (2001), no início do século XXI, os negros representavam apenas 2\% do contingente de universitários nos país.

A Conferência Mundial contra o Racismo, Discriminação Racial, Xenofobia e Intolerâncias Correlatas, convocada pela ONU e realizada em Durban, África do Sul, em 2001, constituiu-se em um dos principais marcos históricos que embasaram as reivindicações do Movimento Negro contemporâneo em torno da implementação de políticas de ação afirmativa, conforme destacam Paula e Heringer (2009).

Embora o movimento pela adoção de cotas para ingresso nas universidades tenha sido impulsionado por agentes sociais afiliados ao movimento negro, outros critérios, além do racial, referenciaram os sistemas adotados. Apesar disto, as principais tensões presentes no debate sobre ações afirmativas, inclusive no âmbito acadêmico, foram articuladas por aqueles que se posicionam contrários à chamada cota racial. A esse respeito, Carvalho (2016, p. 82) argumenta que:

Não faz falta dizer que toda polêmica das cotas se concentra na rejeição de cotas para negros. Após mais de uma década de acompanhamento constante do debate sobre o tema, nunca nos deparamos com um único texto, seja na imprensa escrita, falada ou televisada, de alguém que se posicionasse abertamente contra as ações afirmativas para quaisquer das outras categorias de sujeitos, de escola pública e residentes.

Em um ensaio descritivo e analítico do Mapa das Ações Afirmativas no Brasil, Carvalho (2016) demonstrou que, mesmo antes da aprovação da chamada Lei de Cotas, em 2012, já haviam sido implantados, nas Instituições de Ensino Superior brasileiras, quase uma centena de diferentes sistemas de reserva de cotas, contemplando diferentes critérios. Parte dessas instituições, aderindo ao argumento de que o "problema da exclusão dos negros nas universidades é consequência do fato deles serem majoritariamente pobres” (CARVALHO, 2016, p. 82), adotaram a chamada cota social, 
ou seja, para estudantes de baixa renda e, em alguns casos, também para egresso de escolas públicas $^{1}$.

A Lei Federal 12.711/2012 também foi aprovada contemplando parcialmente tais critérios. Tendo ficado parado por muito tempo no Senado, o projeto de lei prevendo cotas foi aprovado com diversas alterações em relação ao projeto inicial. Foi aprovado tomando como base o critério de ser egresso de escola pública. Pode-se dizer que o critério racial foi contemplado apenas como subcota ${ }^{2}$. Por isso, embora tenha representado conquista importante para redução das desigualdades de oportunidades no acesso ao ensino superior, também foi considerado retrocesso, considerando a perspectiva de cotas com critério racial. A este respeito, Carvalho (2016, p. 101) argumenta que:

A primeira universidade federal que aprovou as cotas foi a Universidade de Brasília, em 2003, e seu modelo foi de $20 \%$ de cotas exclusivamente para negros. Agora, a Lei descarta esse modelo de cotas ditas raciais, que foi fundante de toda essa luta e determina outra ordem de prioridade, definida pelo governo como uma política de cotas sociorraciais.

Embora em meio a tantas polêmicas e limites, segundo dados do IBGE (2016) , é inegável o aumento da participação de estudantes autodeclarados pretos e pardos e de estudantes de baixa renda no ensino superior, nas últimas décadas. De acordo com o IBGE (2016), de 2005 a 2015, houve um aumento de 7,3\% no número de estudantes pretos e pardos no ensino superior. Em 2005 somavam 5,5\% e, em 2015, passaram a somar 12,8\%. No entanto, ainda continuavam a representar menos da metade dos jovens brancos na mesma faixa etária. O percentual de alunos pobres nas universidades públicas passou de 6,2\% para 8,3\%, enquanto nas instituições privadas subiu de $0,8 \%$ para $4 \%$.

Já se pode observar a presença desses estudantes no universo de cursos de grande concorrência, considerados de maior prestígio social, onde, em geral, esses discentes não tinham lugar. Esse aumento certamente está relacionado não apenas aos programas de reserva de cotas, mas também às demais ações afirmativas voltadas à inclusão no ensino superior. Refiro-me, por exemplo, aos cursos do tipo Pré-Vestibular para Negros e Carentes, além do Prouni ${ }^{3}$.

\footnotetext{
${ }^{1}$ Como será visto posteriormente, este foi o caso da UFES, quando adotou seu primeiro sistema de cotas, em 2008.

${ }^{2}$ De acordo com tal legislação, deve-se garantir a reserva de $50 \%$ das matrículas por curso e turno, nas universidades e institutos federais, a alunos oriundos integralmente de escolas públicas de ensino médio, em cursos regulares ou da educação de jovens e adultos. As vagas para pretos, pardos e indígenas são calculadas observando-se o porcentual de PPIs, conforme distribuição populacional em cada Estado da Federação.

${ }^{3}$ Conforme explica Souza (2003), a partir dos anos 1990, multiplicaram-se em todo o país os cursos pré-vestibulares alternativos, gratuitos ou sem fins lucrativos. Neste movimento destacaram-se o Pré-Vestibular para Negros e Carentes (PVNC) e o Educafro, que congregaram centenas de núcleos de preparação de jovens para o vestibular. De acordo com
} 
Algumas questões emergem desse contexto. Como estão posicionados esses estudantes, em quais condições materiais e simbólicas eles se encontram? Como estão construindo relações e sendo percebidos por seus pares em um novo universo de alteridade?

Conforme mencionado no início deste artigo, é com base em tais problemas que a pesquisa em questão foi constituída.

Nas seções seguintes apresentamos e analisamos os dados da pesquisa em foco, tendo como ponto de partida a análise do processo de implementação de cotas na Universidade Federal do Espírito Santo.

\section{O SISTEMA DE RESERVA DE COTAS NA UNIVERSIDADE FEDERAL DO ESPÍRITO SANTO}

A UFES se constitui como única universidade pública situada no estado ${ }^{4}$ do Espírito Santo, apesar do significativo aumento da demanda pelo acesso ao ensino superior, verificado desde a segunda metade dos anos 1990. O atendimento de tal demanda ocorreu, especialmente, pela ampliação de instituições de pequeno porte, não públicas e não universitárias. Segundo dados do MEC/INEP (2010), no Espírito Santo o setor privado de ensino superior registrou um impressionante crescimento, superior ao do país e da região sudeste. Entre 1999 e 2006 o índice de aumento foi de $186 \%$.

A UFES foi uma das Instituições que implantou programa de cotas antes da aprovação da Lei Federal. O programa teve início no ano de 2008, depois de complexo e conflituoso debate, cujo acirramento se deu no ano de 2005. Conforme argumenta Santos (2013), o processo foi iniciado a partir da ação de agentes engajados em núcleos do Movimento Negro do Espírito Santo que, reconhecendo a sub-representação de negros entre os discentes da UFES, especialmente nos cursos mais valorizados socialmente, começaram a empreender ações visando o aumento de tal representação, desde meados da década de 1980. Em seminário realizado no final do ano de 2004, foi composta a “Comissão Pró-Cotas” para propor e acompanhar a implantação de políticas afirmativas na UFES. Tal comissão protocolou, em agosto de 2005, um documento para os Conselhos Superiores da Universidade, contendo uma proposta preliminar de cotas para negros,

dados do Minstério da Educação (BRASIL, 2018), O governo federal instituiu em 2004 o Programa Universidade para Todos (Prouni), destinando bolsas integrais e parciais (50\%) a estudantes considerados de "baixa renda”, em Instituições de Ensino Superior privadas, além de reservar 50\% destas vagas para estudantes negros, indígenas, deficientes físicos e professores do ensino básico.

${ }^{4}$ Além da UFES, alguns cursos, em nível superior, passaram a ser oferecidos recentemente pelo Instituto Federal de Educação (IFES). 
indígenas e estudantes egressos de escola pública. Após intenso processo de debates e articulações, envolvendo também agentes externos, foi aprovado um sistema de cotas aliando-se critérios de renda familiar à situação de egresso de escola pública. O modelo adotado estabeleceu a reserva de $40 \%$ do total de vagas, sendo possível o aumento para 45\% e 50\% naqueles cursos onde a oferta de vagas fosse ampliada. A reserva contemplava estudantes que tinham renda familiar inferior a sete salários mínimos e que tivessem cursado, pelo menos, quatro anos das séries do ensino fundamental e todo o ensino médio em escola pública.

A partir do vestibular de 2012, obedecendo ao que preconiza a Lei Federal $n^{0}$ 12.711/2012, a UFES passou a considerar, imediatamente após a aprovação desta, reserva de $50 \%$ das vagas, observando os critérios definidos pela legislação.

Através da constituição de uma série histórica, com base em dados contidos em relatórios anuais da Comissão Coordenadora do Vestibular sobre os ingressantes nos diferentes cursos da UFES, foi possível avaliar os efeitos dos dois sistemas de cotas no processo de diversificação dos atributos sociais e econômicos dos estudantes que ingressaram na instituição.

No que refere à renda familiar e, considerando o universo total de estudantes (cotistas e não cotistas) foi observado um crescente aumento do número de estudantes oriundos de famílias de menor renda, mesmo antes da implantação do primeiro sistema de cotas. Segundo dados contidos no relatório da Comissão Coordenadora do Vestibular (UFES, 2011), a porcentagem de estudantes com renda familiar até cinco salários mínimos aumentou consideravelmente a partir do ano 2000. Nesse ano, 20,8\% dos estudantes possuíam renda familiar até cinco salários mínimos. Em 2007, este valor aumentou para 40,7\%. Com o advento do sistema de cotas sociais, em 2008, foi alterado para 51\% e, em 2011, chegou a 57,9\%. Nos anos seguintes à implantação do atual sistema de cotas, o percentual continuou a aumentar, ficando em torno de $60 \%$.

No que se refere à possibilidade de maior diversificação relativa à autoidentificação quanto à raça/cor, ao se considerar o universo total de estudantes, só foi possível observar alteração mais significativa após implantação do segundo sistema de cotas. Em 2005, três anos antes do advento de tal sistema, foi observado o ingresso de 36\% de estudantes autodeclarados pardos e 6\% de autodeclarados pretos. Em 2008, o número de pardos se manteve, havendo aumento de 2\% do número de pretos. Em 2011, o número de autodeclarados pretos foi de $9 \%$ e de pardos continuou a ser de 36\%. Após a implementação do segundo sistema de cotas, a situação foi alterada para o seguinte: houve aumento mais expressivo de pardos, de $36 \%$ para $42 \%$ e aumento bem pequeno dos autodeclarados pretos. De 8\% em 2008 para 9\% em 2015. 
Apesar de, na maior parte dos cursos, discentes autoidentificados como pretos e pardos, tenham passado a somar mais da metade dos ingressantes, continuou a ocorrer certa desproporcionalidade. Um aumento mais significativo pode ser observado nos cursos considerados de menor prestígio social, como pedagogia, biblioteconomia, entre outros. Em cursos condizentes com situação oposta, observou-se, por exemplo, certo aumento no número de autoidentificados como pardos. Porém, em cursos como Medicina e Direito, os estudantes autoidentificados como brancos permaneceram constituindo maioria entre os ingressantes. No curso de Medicina houve, inclusive, redução do número de estudantes autoidentificados como pretos.

Vale lembrar que, no quadro populacional do Estado do Espírito Santo, de acordo com dados do último censo do IBGE (2010), os autoidentificados como pardos e pretos constituem maioria, somando 56, $9 \%$.

Mesmo considerando os limites dos sistemas de cotas adotados pela UFES, no que se refere, sobretudo, à perspectiva da inclusão de estudantes negros, a possibilidade de ingresso por tais sistemas, aliada a outros fatores, tem se constituído como fundamental para a concretização do projeto de ingresso no ensino superior por parte dos estudantes entrevistados na pesquisa em foco.

Reconhecendo que os números não falam por si próprios, isto é, são apenas indícios, nas seções seguintes serão consideradas para análise as narrativas dos próprios estudantes.

\section{PROJETOS DE ESCOLARIZAÇÃO, ACESSO AO ENSINO SUPERIOR E AÇÕES AFIRMATIVAS}

Os estudantes em questão, em geral, representam a primeira experiência familiar de ingresso no ensino superior, em uma instituição pública. O projeto de ingressar na universidade foi construído, para parte desses discentes, especialmente os de maior faixa etária, de forma não naturalizada, mais especificamente, no processo que Berger e Luckman (2001) denominaram “socialização secundária”. Experiência bastante semelhante foi evidenciada por Mongim (2015) em um estudo dedicado à análise de itinerários sociais de estudantes beneficiários do Programa Universidade para Todos (Prouni). A autora demonstrou que, para a maior parte dos entrevistados por ela, "o projeto de ingresso no ensino superior ocorreu a partir da interação com diferenciados agentes de mediação social, posicionados, em quadros institucionais que ultrapassam os limites das redes de relações da família nuclear” (MONGIM, 2015, p.931).

No presente estudo, só foi possível observar experiência diferenciada entre parte dos estudantes do curso de Medicina e entre os mais jovens do curso de Arquitetura, Direito e de 
Ciências Sociais. Para alguns estudantes do curso de Medicina, tornar-se médico(a) foi concebido como um sonho iniciado desde a infância, a partir da própria experiência dos estudantes em contato permanente com profissionais da área.Em alguns casos, devido à necessidade de cuidados com a própria saúde. Em outros, com a saúde de algum familiar, conforme pode ser observado no relato a seguir de uma estudante do primeiro período do curso.

Comecei a pensar em Medicina desde nova; na quinta, sexta série já tinha [isso] em mente, por ter a minha irmã mais velha, com problemas, com retardo mental. Meu irmão também teve um acidente, quase amputou a perna, minha mãe tem pressão alta, [está] sempre passando mal. Então, [eu] estava sempre em contato, desde cedo, acompanhando no hospital, vendo a correria dos enfermeiros, médicos, assistindo um pouco de televisão. Encantei-me pela Medicina, [tornou-se] um sonho.

No que se refere à objetivação do projeto de ingresso no ensino superior pode-se dizer que ocorre,sobretudo, a partir das interações com mediadores sociais, posicionados nas diferentes redes de sociabilidade constituídas ao longo dos itinerários em questão. Os referidos agentes podem ser mediadores personalizados, como membros da família extensa, professores e colegas de trabalho, mas também, muitas vezes, mediadores do tipo formal-legal, conforme tipologia definida por Neves (2008).

$\mathrm{Na}$ maioria dos casos, os estudantes consideram de grande importância as relações estabelecidas com agentes institucionais de mediação social, afiliados a cursos do tipo PréVestibular Para Negros e Carentes. No caso de Sônia, estudante do curso de Medicina, tal processo ocorreu em dois desses cursos, como pode ser observado no relato a seguir.

Fiz os dois ao mesmo tempo, o PUPT e o Dandara. Isso a semana toda. No sábado, tinha de manhã também. Às vezes, coincidiam os dois. Faltava um, ia no outro. À tarde, fazia inglês no Idiomas, que é um projeto também do Estado. No domingo de manhã, tinha também um cursinho, na igreja, só de discursiva de biologia e química. Eu também participava. Então, era assim minha rotina.

Também há, na maior parte dos casos considerados, o explícito reconhecimento do quanto o sistema de cotas constituiu-se como fator fundamental para a objetivação do projeto de ingresso na universidade. Trata-se de possibilidade significativamente valorizada diante das expectativas em torno de uma vida melhor. 


\section{ENTRE COMEMORAÇÕES, TENSÕES E CONSTRANGIMENTOS: O PROCESSO DE INGRESSO NA UNIVERSIDADE PELO SISTEMA DE COTAS}

Para os discentes dos cursos considerados, a inserção em um novo universo de significados traz à tona sentimentos e sentidos diversos. Ingressar na universidade se constitui em motivo de grande orgulho e comemoração. Muitos destacam, inclusive, o fato de serem os únicos da família a ingressarem em Instituição de Ensino Superior federal. O ingresso no curso superior é concebido, inicialmente, com base na crença de que a universidade é o espaço social da competência e do prestígio. Para esta estudante, que no momento da entrevista estava no terceiro período do curso de Ciências Sociais, trata-se de um lugar sagrado.

Eu não acreditava, eu achava que era impossível, e assim de uma hora para outra eu consegui. Quando entrei aqui era sonho realizado. Cada pedacinho desse chão pra mim era sagrado. Eu falava que era um sonho impossível. Tudo pra mim foi sagrado. Do momento de fazer a matricula à hora de pegar a senha. Eu não acreditava. Eu só acreditei que eu estava aqui depois que eu estava estudando. Foi sagrado.

A posição de universitário é assumida, conforme destacado, com muito orgulho, porém também traz a tona muitos constrangimentos, que são reveladores, muitas vezes, do dilema inerente à posição constituída de universitário cotista. Por isso, ao mesmo tempo em que o acesso à nova posição é comemorado, a percepção da alteridade pode se apresentar como um desafio.

Para muitos, há a evidente percepção que estão em sacrifício. Com base no que discutem Mauss e Hubert (2005), ao demonstrarem a importância da dimensão não propriamente religiosa de tal ato, pode-se afirmar que o processo de mobilidade é orientado pelos valores associados à ética do sacrifício. Só parece ser possível o deslocamento de posição social a partir da valorização de um sistema que exige não só dedicação, mas a abstinência relativa a determinadas práticas concebidas como propiciadoras de prazer e bem-estar. É preciso dormir pouco e estudar nos fins de semana, não sendo possível reservar tempo para o lazer.

Aqueles que assumem a posição de estudante-trabalhador destacam o quanto se torna difícil a tarefa de conciliar os estudos com o trabalho, como é o caso de Ricardo.

Eu sinto muita dificuldade, porque tem muita gente que faz curso superior, e já tem outra cabeça e eu senti muita dificuldade, até porque eu trabalho por escala, um dia de manhã, trabalho $12 \mathrm{~h}$ e depois tem que vim pra faculdade. Estou cheio de falta porque chego atrasado. Tem dia que saio daqui, pego a viatura e largo só no outro dia, fico muito cansado. Mais, às vezes, eu penso: Poxa, demorei tanto pra consegui pra desistir agora! Eu gosto de ir até o fim, mas é muito puxado prá mim. Tem alguns professores que cobram muito e não querem saber a condição do aluno, não querem saber se você 
está a 12h trabalhando, qual é a sua dificuldade, eles pedem e pronto. Pra ele é fácil, mas pra gente não é, tem que ter sacrifício pra conseguir.

As práticas representativas de uma ética do sacrifício, por parte dos estudantes, aproximamse da proposta de Mauss e Hubert (2005) ao relacionarem sacrifício e dádiva e explicitarem que:

[...] Em todo sacrifício há um ato de abnegação, pois quem se sacrifica se priva e se dá. Essa abnegação lhe é mesmo frequentemente imposta como um dever. [...] Mas essa abnegação essa submissão não deixam de ter um lado egoísta. Se o que sacrifica dá alguma coisa de si, ele não se dá; ele se reserva prudentemente. É que se ele dá, é em parte para receber. 0 sacrifício

se apresenta, então, sob um duplo aspecto. E um ato útil e uma obrigação. O desinteresse se mescla ao interesse. Por isso ele foi frequentemente concebido sob a forma de um contrato. (MAUSS E HUBERT, 2005)

No caso em questão, a conciliação entre o caráter obrigatório e utilitário do sacrifício parece evidente. É necessário e também obrigatório privar-se para ser recompensado. Postula-se a crença numa obrigatória recompensa diante do ato de dar-se em sacrifício, nos termos da moral da dádiva, pautada nas obrigações de dar-receber e retribuir. Se me dou em sacrifício, receberei obrigatoriamente uma recompensa. Fazer um curso superior, deslocando-se para uma posição social de maior prestígio, constitui-se para estes estudantes a grande recompensa ${ }^{5}$.

Os discentes que não exercem atividades remuneradas destacam as dificuldades materiais para continuarem estudando, conforme é possível observar no relato desta estudante do quarto período do curso de Arquitetura e Urbanismo:

Durante o ensino médio eu trabalhei e juntei um dinheiro que deixei na minha poupança como emergência. Eu me senti obrigada a comprar um computador, um notebook. A gente estava começando uma matéria que exigia computador. Eu cheguei para o professor, meio que brincando, e falei: Professor, e quem não tem um computador, como é que faz ? Aí ele virou e falou assim: "Ah! Você arruma um, né? Arruma!”- Como se fosse a coisa mais simples de se comprar. Minha mãe não podia me dar, meus pais não podiam me dar. E aí eu fui, peguei o dinheiro que tinha, não chegava nem a metade que eu precisava, pois o computador exige um processador melhor para rodar programas.

\footnotetext{
${ }^{5}$ Concepção bastante semelhante foi assumida por Mongim (2016) em estudo realizado com estudantes que ingressaram em uma Instituição de Ensino Superior não pública, mediante programa de bolsas.
} 
Além das dificuldades financeiras, não superadas com os ganhos oriundos dos programas de assistência estudantil, os relatos revelam situações nas quais os discentes cotistas não se sentem, muitas vezes, autorizados a estarem na posição que passaram a assumir. Por essa via, o sentido do pertencimento é perpassado por muitas tensões e constrangimentos. O processo de mobilidade assume significados expressivos dos prazeres da conquista, mas também tradutores de dores e sofrimentos.

Ao relatar sua experiência ao ingressar na universidade, Solange, discente do primeiro período do curso de Direito, fez a seguinte declaração:

Foi muito ruim, foi bem decepcionante no início, porque eu achava que seria como minha turma no IFES [Instituto Federal do Espírito Santo], que era muito unida, tipo família mesmo, todo mundo muito, muito unido. Claro que tinham desavenças também. Só que aqui, na UFES, no curso de Direito, parece uma competição, parece que tem pessoas ali que usam a cabeça das outras como um degrau para subir. Eu brinco com a mamãe que eu fui jogada em um ninho de cobras sem ter conhecimento do que eu estava fazendo. Começou a ser muito frustrante para mim, porque você vê que é um curso de Direito focado para uma parte que é minoria. Eu vim da periferia, eu sei que o que eles falam é lindo, mas não acontece para a maior parte da população. Eu sou apaixonada pelo meu curso, mas não sei se vou consegui me habituar com as pessoas, com o meio, que é uma coisa de um competindo com o outro, um contra o outro - não necessariamente com todo mundo, tanto que tem pessoas na sala com quem eu converso, só que tem pessoas que não faço questão, porque passam na rua e fingem que não me conhecem .

Apesar de, em alguns casos, os estudantes tenderem, por efeitos de posição, a secundarizar as dificuldades presentes no processo de pertencimento a um novo espaço simbólico, são significativamente evidentes as práticas representativas de estigmatizacão, discriminação e exclusão nas relações interpessoais por parte de grupos ou agentes institucionais. Tais práticas são mais evidentes entre os estudantes inscritos nos curso de Direito e de Medicina, porém, não deixam de ser observadas também entre os do curso de Ciências Sociais e de Arquitetura e Urbanismo.

Ao se referir, por exemplo, ao ingresso de estudantes cotistas no curso de Medicina, Sandro, estudante que, no momento da entrevista, cursava o sexto período deste, fez as seguintes considerações:

No início, no primeiro e no segundo períodos, ainda tem desdém, diferencial. Eles não se agregam muito. Fica aquela divisão. Uma ala é cotista, outra não cotista. Então, geralmente, fica aquele pessoal que veio de determinada escola particular, de uma 
mesma turma, de curso integral que pagava 1500 reais, sei lá quanto, que já se conhecia, se unem e fazem ali um círculo de amizade. Os demais geralmente são mais simples, mais acanhados, menos favorecidos; em questão de imagem, de estética, são os mais simplesinhos. É meio como que tivesse caracterizando assim: aquele ali é pobre, aquele ali é o cotista, mesmo já sabendo pela lista que sai, né? Quando chega o terceiro, quarto período em diante, já começa a dar aquela homogeneizada, as matérias começam a ser completamente novas para todas as turmas e os cotistas começam a se manter no mesmo nível que os não cotistas, tipo assim, disputando o primeiro, o segundo lugar em termos de notas. Começa a homogeneizar também [por] ter a questão da maturidade. No início, os nãos cotistas vêm cheios de preconceito. Percebo amizades entre cotista e não cotistas, mas não no início, só bem depois.

Um dos discentes entrevistados, inscrito no segundo período do curso de Direito, relatou que, a princípio, não percebia atitudes preconceituosas em relação aos cotistas. Buscava, inclusive, integrar-se aos grupos de estudantes não cotistas. Um episódio, no entanto, o fez perceber situação inversa. Segundo relatou, ele se encontrava conversando informalmente com estudantes do mencionado grupo, quando, ao comentarem a respeito do furto de uma bicicleta nas dependências da universidade, um dos colegas afirmou que "só podia ter sido um cotista”. Os demais o apoiaram em sua opinião. Ao relatar tal fato, não conseguiu esconder o quanto se sentiu ofendido, tomando, posteriormente, a decisão de se afastar daquele grupo.

Ainda em relação a estudantes do curso de Direito, foi possível identificar, nos relatos, a formação de um grupo denominado "Direito Vip”. A esse respeito, Santos (2014, p. 311), em estudo onde discute a relação raça/classe no processo de constituição do sistema de cotas na UFES, faz a seguinte consideração, com base nos relatos de seus entrevistados:

O "Direito Vip" foi criado "secretamente" no Facebook por alunos de classe média e ex-estudantes de escolas privadas de grande prestígio e onerosas do Espírito Santo, como Darwin e Leonardo da Vinci. O objetivo de seus proponentes era se distinguir de cotistas e pobres. Para Marta, muitos dos que não fazem parte do "Direito Vip" ficam isolados, apesar de ter professores e alunos do curso que lutam contra isso ou por uma universidade menos elitista.

Tais práticas nos remetem às reflexões de Elias e Scotson (2000) a respeito dos estabelecidos e os outsiders. Essas categorias, de caráter relacional, são discutidas pelos mencionados autores em uma etnografia das relações de poder na comunidade de Winston Parva (nome fictício), próxima de Leicester, Inglaterra, localidade marcada pela existência de um grupo de moradores antigos da aldeia, os “estabelecidos”, que se colocavam como pessoas de “valor 
humano mais elevado" do que o dos moradores do loteamento, construído em época mais recente, os outsiders, estigmatizados pelos primeiros. As análises dos autores apontam ser graças a um maior potencial de coesão que os antigos residentes de Winston Parva, os “estabelecidos”, conseguiram reservar para as pessoas de seu tipo os cargos importantes das organizações locais, como o conselho, a escola ou o clube, e deles excluir firmemente os moradores de outras áreas, aos quais, como grupo, faltava coesão. A exclusão e a estigmatização dos outsiders pelo grupo estabelecido constituíam-se em armas poderosas para que este preservasse sua identidade e afirmasse sua superioridade, mantendo os outros firmemente em seu lugar.

No caso em análise, as relações entre cotistas e não cotistas tendem a ocorrer de forma tensa e desigual, tal como entre os estabelecidos e outsiders analisados por Elias e Scotson (2000). Os que discriminam também compartilham da percepção de fazerem parte de algum grupo de "valor humano mais elevado”, percepção esta que parece assentada em relações sociais estabelecidas para além dos muros da faculdade, amparadas em um sistema social que se estrutura de forma hierárquica, excludente e racista, conforme destacam autores como Da Matta (1987), Munanga (1996), entre outros.

\section{A CONDIÇÃO DE SER COTISTA NEGRO}

Se, como visto, para os discentes cotistas o sentido de pertencimento tende a ser perpassado, muitas vezes, por tensões e constrangimentos, tal processo parece se exacerbado para os que convivem com a condição de ser cotista e ser negro. Isto porque, conforme observa Munanga (2003), o racismo hierarquiza, desumaniza e justifica a discriminação existente. Alguns relatos de discentes negros são bastante expressivos desta tensão, como o desta aluna que, no momento da entrevista, estava no terceiro período do curso de Direito.

No semestre passado pensei muito em largar o curso por conta de situações que aconteceram lá no curso. Situações bem delicadas, inclusive de professores também sendo tipo muito racista dentro da sala de aula. Então, eu pude perceber um racismo que mesmo, por exemplo, que eu sofresse na escola, não era assim. As pessoas que me insultavam na escola, elas me insultavam mas, por exemplo, eu não me sentia isolada de tudo, porque, querendo ou não, tinham outras pessoas lá também que, como era majoritariamente negro, então a gente sempre se reunia, e aí chegou aqui, isso foi ao contrário, entende? as pessoas não me insultavam, mas elas me isolavam, sabem? eles falam “nós somos favoráveis às cotas”, mas, por exemplo, eu escolho meu grupo e meu grupo não tem cotistas. Isso me desmotivou muito na aula. Eu relutei muito em decidir. Vivi situação de falar alguma coisa e as pessoas debocharem de mim, de achar 
que você está falando tudo errado, de achar que não é aquilo, aí depois o professor comenta: "nossa que legal, hein!?você respondendo isso!” Quer dizer que eu não estudo, sabe? Mesmo, querendo ou não, essa coisa ainda paira ainda lá. Eu sempre digo lá no Coletivo Negrada, lá no Direito é explícito o que é o racismo no Brasil. A pessoa não fala com você, você passa diz “bom dia!” E o outro não te cumprimenta, finge que não te vê, te olha de cara feia, mas diz que não é racista sabe? Diz: "Eu não estou te chamando de macaca, não estou fazendo nada com você”. Então, eu tive situações delicadas com professores, enfrentei situações assim muito difíceis.

O acesso à posição de estudante universitário parece não eliminar, nem reduzir, a situação de discriminação racial vivenciada por esses discentes, como também observou Santos (2004), em estudo anteriormente mencionado. Embora relativos a contextos diferentes, estudos produzidos por outros pesquisadores também demonstraram a impossibilidade de eliminação do racismo pela ascensão social. Em um estudo com radialistas negros, que ascenderam à profissão, Borges Pereira (1967) demonstrou o quanto continuaram a sentir os efeitos da discriminação racial, mesmo sendo libertos das injunções econômicas. Se o acesso a bens materiais pode contribuir para melhoria da qualidade de vida, não é o suficiente para assegurar condições de reconhecimento identitário, tão fundamental à existência, conforme demonstrou Taylor (1998).

Na situação específica de acesso do negro ao espaço universitário, é importante se reportar às considerações de Carvalho (2007) sobre o confinamento racial presente nas universidades brasileiras. Segundo o mencionado autor (2007, p. 99),

O Brasil também fez parte do grande processo de racialização inferiorizante dos negros ou não-brancos durante pelo menos meio século. O resultado dessa política arianizante iniciada na década seguinte após a Abolição da escravatura e que durou até os anos 40 foi a expulsão, da escola e da carreira de educador, de milhares de negros. Uma desvantagem escolar concreta, portanto, foi promovida pela nossa elite branca racista na primeira metade do século XX.

Foi nesse clima de arianização, agravado pela ideologia da democracia racial, que as universidades brasileiras se constituíram como espaços institucionais brancos, excludentes e racistas. Conforme observa Carvalho (2007) nenhuma medida foi adotada, anteriormente às políticas de cotas raciais, para corrigir o processo de exclusão racial que caracterizou as universidades desde que foram fundadas. Ao contrário, "houve grande hostilidade e rejeição à presença de vários quadros negros importantes nos postos docentes” (CARVALHO, 2007, p. 99). 
Essa reflexão é importante, pois nos mostra como têm sido produzidas, no espaço acadêmico, as interpretações sobre as relações raciais no Brasil. Carvalho (2007) chama atenção para o importante fato de que as teorias que negaram o racismo nasceram exatamente desse contexto acadêmico, como é o caso da tese acerca da democracia racial. Segundo o autor:

[...] foi justamente desse ambiente segregado que saíram todas as teorias que negam a existência de segregação racial no Brasil. Se tratarmos sobre as relações raciais, é aceitável que demandemos dos intérpretes não apenas a sua leitura da desigualdade racial existente na sociedade 'lá fora', mas também que se posicionem acerca da realidade de segregação de que eles mesmos participam (CARVALHO, 2007, p. 33).

Diante de tais considerações, é importante destacar que, se o processo de ascensão social não elimina a situação de discriminação racial, quando ocorre em um ambiente onde se produz uma situação de confinamento racial, pode-se constituir em desafio ainda maior. Considerando que os docentes e pesquisadores que constituem as universidades brasileiras têm sido parte do problema racial, parece que "somente a partir do momento em que nos enxergarmos como parte do problema poderemos passar a fazer parte da sua solução” (CARVALHO, 2007, p. 102).

Apesar da persistência de relações perpassadas por preconceitos e discriminação racial, pode-se observar certo movimento, ainda que restrito, voltado para o rompimento da situação de confinamento racial no espaço acadêmico. Conforme destacado por Mongim e Trindade (2018), além da adoção de sistema de reserva de cotas, na UFES tem sido estimulado o debate e maior produção de pesquisas e estudos em perspectiva antirracista.Vale também ressaltar a importância da inclusão, em diferentes cursos de licenciatura, pela UFES e outras Instituições de Ensino Superior, de disciplina voltada para a educação das relações étnico-raciais. Ainda nessa perspectiva, foi realizada em setembro de 2008, a I Conferência de Ações Afirmativas da UFES, organizada pela Pró-Reitoria de Assuntos Estudantis e Cidadania em parceria com diferentes agentes afiliados a núcleos acadêmicos e a organizações da sociedade civil. Também vale destacar que desde o ano de 2012, parte dos estudantes da UFES tem-se articulado em coletivos negros, como o Coletivo Negrada. ${ }^{6}$

\footnotetext{
${ }^{6}$ Trindade (2016, p. 102), com base nos relatos de seus entrevistados, explica que "o Coletivo Negrada foi criado no ano 2012, em resposta às diversas situações recorrentes de racismo e a exclusão sofrida pelos discentes negros dentro da universidade".
} 


\section{CONSIDERAÇÕES FINAIS}

Conforme busquei demonstrar ao longo deste artigo, para os discentes em questão, o ingresso na universidade constitui-se em evento significativamente valorizado. Assim, mesmo diante das tensões e constrangimentos que perpassam o sentido do pertencimento, esses estudantes valorizam de forma significativa a oportunidade de estarem em um espaço no qual, para muitos, não era sequer concebida como possível.

A interação com agentes de mediação do tipo formal, situados nos programas de reserva de cotas ou de cursos do tipo Pré-Vestibular para Negros e Carentes, constituiu-se como de fundamental importância para que fosse possível o ingresso no ensino superior. Por essa via, o propósito das ações afirmativas em “tratar desigualmente situações desiguais” (MUNANGA, 2003) para compensar as desvantagens produzidas por diferentes formas de discriminação, apresenta-se como satisfatório na experiência desses discentes. No entanto, como visto, as relações que se estabelecem no processo de ingresso e de permanência na universidade, são, em boa parte, evidentemente contrárias às concepções que ancoram a formulação de políticas de ação afirmativa. Se há, por parte dos estudantes, dificuldades de ordem financeira (nem sempre superadas com os programas de assistência estudantil), os desafios no que se refere à valorização da diversidade e do reconhecimento identitário, são também amplos e significativos Embora seja a universidade um espaço marcado por uma pretensão de universalidade de concepções e valores, onde se faz possível estabelecer novas relações e experiências com diferentes agentes, o sentido de pertencimento para discentes na posição de cotistas e, em especial, de cotistas negros, tem sido perpassado pelo predomínio de concepções e práticas eurocêntricas, hierarquizantes e racistas.

Diante de tal contexto, parte dos estudantes cultiva a crença de que as tensões podem ser superadas pela demonstração individual de que são capazes de obter resultados acadêmicos satisfatórios. O processo de superação é, em geral, orientado por valores associados à ética do sacrifício e do esforço pessoal. Assim, em busca do alcance de resultados satisfatórios, muitos se colocam em sacrifício, abstendo-se de simples eventos cotidianos tradutores de prazer e satisfação, como dormir bem e se alimentar em horários adequados. Constrói-se a crença na possibilidade da permanência e da conclusão do curso superior como uma vitória pessoal, com a certeza de que os compromissos pautados nas relações de dar, receber e retribuir, tradutores da moral da dádiva (MAUSS, 1974) estão sendo cumpridos. 
No entanto, outros estudantes cultivam a crença na superação dos desafios pela via da organização coletiva. Organizam-se em coletivos imbuídos desses propósitos, em especial, em Coletivos de estudantes negros.

Por essas considerações, resta acrescentar que, se há consenso em torno da necessidade de que as condições materiais de permanência sejam asseguradas aos estudantes, o investimento sistemático no combate ao racismo e a toda e qualquer forma de discriminação e exclusão parece ser, de igual forma, concebido como urgente e necessário. 


\section{REFERÊNCIAS}

BERGER, P. L.; LUCKMAN, T. A construção social da realidade. 22. ed. Petrópolis: Vozes, 2001.

BERTAUX, D. Lesrécits de vie: perspectives ethnosociologiques. Paris: Nathan, 1997.

BORGES PEREIRA, João B. Côr profissão e mobilidade: o negro e o rádio de São Paulo. São Paulo: Pioneira: Edusp, 1967.

BRASIL. Ministério da Educação. Instituto Nacional de Estudos e Pesquisas Educacionais Anísio Teixeira (INEP). Estatísticas do ensino superior. Disponível em: <http://www.inep.gov.br>. Acesso em: 30 mar. 2010. dez. 2018.

Prouni - Programa Universidade Para Todos. Disponível em: <http://siteprouni.mec.gov.br/>. Acesso em: 13

CARVALHO, J. J.O confinamento racial do mundo acadêmico brasileiro. PADÊ: estudos em filosofia, raça, gênero e direitos humanos, UniCEUB, FACJS, v. 2, n. 1, 2007, p. 31-50.

. A política de cotas no ensino superior. Ensaio descritivo e analítico do mapa das ações afirmativas no Brasil. Instituto de Inclusão no Ensino Superior e na Pesquisa. CNPQ/Universidade de Brasília, 2016.

CARVALHO, M. M; WALTENBERG, F. Desigualdade de oportunidades no acesso ao ensino superior no Brasil: uma comparação entre 2003 e 2013. Econ. Apl., Ribeirão Preto , v. 19, n. 2, p. 369-396, jun. 2015.

DA MATTA, R. Digressão: a fábula das três raças, ou o problema do racismo à brasileira. In: DA MATTA, R. Relativizando: uma introdução à antropologia social. Rio de Janeiro: Rocco, 1987. p. 58-85.

DAUSTER, T. "Uma revolução silenciosa”: notas sobre o ingresso de setores de baixa renda na universidade. In: CONGRESSO LUSO-AFRO-BRASILEIRO DE CIÊNCIAS SOCIAIS, 8. Anais... Coimbra, 2004. Disponível em: <www.ces.uc.pt/lab2004/pdfs/TaniaDauster.pdf >. Acesso em: 04 dez. 2019.

ELIAS, N.; SCOTSON, J. Os estabelecidos e os outsiders. Rio de Janeiro: Jorge Zahar, 2000.

HENRIQUES, R. Desigualdade racial no Brasil: evolução das condições de vida na década de 90. Texto para Discussão 807. Rio de Janeiro: Instituto de Pesquisa Econômica Aplicada, 2001.

HERINGER, R; FERREIRA, R. Análise das principais políticas de inclusão de estudantes negros no ensino superior no Brasil no período 2001-2008. In: PAULA, Marilene de; HERINGER, Rosana. (Org.). Caminhos convergentes: estado e sociedade na superação das desigualdades raciais no Brasil. Rio de Janeiro: Heinrich BöllStiftung, 2009. p. 137-196.

INSTITUTO BRASILEIRO DE GEOGRAFIA E ESTATÍSTICA. Censo demográfico. Rio de Janeiro: IBGE, 2010. IBGE, 2016.

Síntese de Indicadores Sociais: uma análise das condições de vida da população brasileira. Rio de Janeiro,

MAUSS, Marcel. Ensaio sobre a dádiva: formas e razão da troca nas sociedades arcaicas. In: Sociologia e Antropologia. v. 2. São Paulo: EDUSP, 1974.

; HUBERT, H. Sobre o sacrifício. São Paulo: Cosac Naify, 2005.

MONGIM, A. B. Crescimento pessoal, mediação e sacrifício: itinerários sociais de estudantes beneficiários do Prouni, Educ. Soc., Campinas, v. 36, n. 133, p. 927-943, dez. 2015

. Diversidade, raça e classe: atributos sociais de discentes beneficiários de programa de reserva de cotas. Realis - Revista de Estudos Antiutilitarisas e Poscoloniais, v. 1, n. 1, jan./jun. 2012.

; TRINDADE, L. R. Estudantes universitários negros: diversidade e reconhecimento identitário. Dossiê Africanidades Transatlânticas. Revista do Arquivo Público do Estado do Espírito Santo, ano, n. 3, jan./jun. 2018.

MUNANGA, K. O anti-racismo no Brasil. In: MUNANGA, Kabengele. (Org.). Estratégias e políticas de combate à discriminação racial. São Paulo: Edusp: Estação Ciência, 1996. p. 79-94.

Política de ação afirmativa em benefício da população negra no Brasil: um ponto de vista em defesa de cotas. In: SILVA, P. B. G., SILVÉRIO, V. R. (Orgs.). Educação e ações afirmativas: entre a injustiça simbólica e a injustiça econômica. Brasília: INEP/MEC, 2003. p. 105-123.

NEVES, D. P. (Org.). Mediação social e mediadores políticos. In: Desenvolvimento social e mediadores políticos. Porto Alegre: Editora da UFRGS, 2008. p. 21-44. 
PAULA, M.; HERINGER, R. (Org.). Caminhos convergentes: estado e sociedade na superação das desigualdades raciais no Brasil. Rio de Janeiro: Heinrich BöllStiftung, 2009. p. 137-196.

SANTOS, S. P. dos. “Os ‘intrusos’ e os ‘outros’ quebrando o aquário e mudando os horizontes”: as relações de raça e classe na implementação das cotas sociais no processo seletivo para cursos de graduação da UFES - 2006-2012. 2014. 389 f. Tese (Doutorado em Educação) - Universidade Federal do Espírito Santo, Vitória, 2014.

SOUZA, S. R. O pré-vestibular para negros como instrumento de política compensatória - o caso do Rio de Janeiro. In: Oliveira, Iolanda de. (Org.). Relações Raciais e Educação: novos desafios. Rio de Janeiro: DP\&A Editora, 2003.

SOUZA e SILVA, J. “Por que uns e não outros?” Caminhada de estudantes da maré para a universidade. Tese (Doutorado em Educação) - Faculdade de educação, Puc-Rj, Rio de Janeiro, 1999.

TAYLOR, C. A política de reconhecimento. In: TAYLOR, C. (Org.). Multiculturalismo. São Paulo: Loyola, 1998.

TRINDADE. L. R. Universitários negros: acesso ao saber escolar e o processo de (re)construção da identidade. Dissertação (Mestrado em Ciências Sociais) - Universidade Federal do Espírito Santo, Vitória, 2016.

UNIVERSIDADE FEDERAL DO ESPÍRITO SANTO. Comissão Coordenadora do Vestibular. Vestibular UFES 2011 (Vitória, Alegre e São Mateus): Perfil dos Inscritos e dos Ingressantes. Vitória, 2011. 


\section{RESUMO}

Este artigo tem como objetivo analisar o processo de ingresso e de permanência na universidade de discentes cotistas, destacando desafios, tensões e constrangimentos. Trata-se de estudo etnográfico, com utilização de entrevistas de narrativas de vida. O ingresso na universidade constitui-se em motivo de comemoração para os discentes que, em geral, reconhecem a importância do sistema de cotas para esse fim. No entanto, além das dificuldades financeiras, convivem com episódios de estigmatização e discriminação. Parte dos estudantes busca superar tais desafios através da organização coletiva. Outros, através de sacrifício pessoal. Assim, tão fundamental quanto assegurar as condições materiais de permanência na universidade, também o é investir no combate a toda e qualquer forma de discriminação.

Palavras-chave: Sistema de cotas. Universidade. Tensões e Constrangimentos.

\section{BETWEEN COMMEMORATIONS, TENSIONS AND CONSTRAINTS: ENTERING THE UNIVERSITY BY THE QUOTA SYSTEM}

\section{ABSTRACT}

This article aims to analyze the process of admission and staying in the university of quota students, evidencing challenges, tensions and constraints. This is an ethnographic study, with the use of interviews of life narratives. Admission to the university is a reason for commemoration for students who, in general, recognize the importance of the quota system for this purpose. However, in addition to financial difficulties, they coexist with episodes of stigmatization and discrimination. Some of the students seek to overcome such challenges through collective organization. Others, by personal sacrifice. Thus, as fundamental as ensuring the material conditions of permanence in the university, so is to invest in the fight against any form of discrimination.

Keywords: Quota system. University. Tensions and constraints.

\section{ENTRE COMEMORACIONES, TENSIONES Y CONSTRANGIMENTOS: INGRESO EN LA UNIVERSIDAD POR EL SISTEMA DE COTAS}

\section{RESUMEN}

Este artículo tiene como objetivo analizar el proceso de ingreso y de permanência em la universidad de discentes cotistas, destacando desafíos, tensiones y limitaciones. Se trata de estudio etnográfico, conutilización de entrevistas de narrativas de vida. El ingreso em la universidad se constituye en motivo de conmemoración para los discentes que, en general, reconocen la importancia del sistema de cuotas para ese fin. Sin embargo, además de las dificultades financieras, conviven com episodios de estigmatización y discriminación. Parte de los estudiantes busca superar estos desafíos através de la organización colectiva. Otros, por el sacrifício personal. Así, tan fundamental como asegurarlas condiciones materiales de permanencia en la universidad, también lo es invertiren el combate a toda forma de discriminación.

Palabras clave: Sistema de cuotas. Universidad. Tensiones y limitaciones. 